\title{
Electrospun cyclodextrin nanofibers as precursor for carbon nanofibers
}

\author{
Bhushan Patil ${ }^{1, *}$, Zehra Irem Yildiz ${ }^{1}$, and Tamer Uyar $^{1,2, *}$ (1) \\ ${ }^{1}$ Institute of Materials Science and Nanotechnology, Bilkent University, Ankara 06800, Turkey \\ ${ }^{2}$ Department of Fiber Science and Apparel Design, College of Human Ecology, Cornell University, Ithaca, NY 14853, USA
}

Received: 15 September 2019

Accepted: 17 January 2020

Published online:

27 January 2020

(C) Springer Science+Business Media, LLC, part of Springer Nature 2020

\begin{abstract}
The carbon nanofibers (CNF) based on the electrospun polymer-free hydroxypropyl- $\beta$-cyclodextrin $(\mathrm{HP} \beta \mathrm{CD}$ ) nanofibers were obtained by the combination of chemical and thermal (pyrolysis) treatment. The thermal and chemical decomposition of HP $\beta C D$ makes it challenging to obtain persistent CNF from $\mathrm{HP} \beta C D$ nanofibers. The chemical treatment of HP $\beta C D$ nanofibers by using $0.6 \mathrm{mM} \mathrm{H}_{2} \mathrm{SO}_{4}$ partially dissolves nanofibers and resulted in fused CNF while direct pyrolysis of $\mathrm{HP} \beta C \mathrm{CD}$ nanofibers totally ruins the nanofiber structure and produces char. The partial chemical treatment of HP $\beta C D$ nanofibers with $10 \mu \mathrm{M}$ $\mathrm{H}_{2} \mathrm{SO}_{4}$ dehydrates the top layer of the nanofibers, and a shield-like structure is formed which helps to retain the fibrous morphology during the pyrolysis. The diameter of HP $\beta C D$ nanofibers was reduced after carbonization process where CNF having average diameter of $380 \pm 150 \mathrm{~nm}$ were obtained. The presence of typical D and G Raman bands and XRD peak at $2 \theta \sim 26^{\circ}$ further validates CNF formation from HP $\beta C D$ nanofibers. The oxygen content is decreased from 34.7 to $5.8 \%$, and carbon content increased from $62.3 \%$ to $94.2 \%$ after transformation of HP $\beta C D$ nanofibers into CNF. To the best of our knowledge, for the first time, this study reports the use of electrospun polymer-free HP $\beta C D$ nanofibers as a precursor to produce CNF.
\end{abstract}

\section{Introduction}

Carbon is of an interesting element due to its transformable properties by controlling the allotropes such as graphite, fullerenes, graphene, carbon nanotube, and diamond [1]. The carbon materials exist in various dimensions such as zero-dimensional (i.e., quantum dots), one-dimensional (i.e., carbon nanotubes, carbon fibers), and two-dimensional (i.e., graphene) [2] having different conductivity [3, 4], optical properties [5], thermal properties [6], and mechanical properties [7]. Nanostructure forms of carbon have numerous applications in the energy [8, 9], sensors [10], biomedical [11], aeronautics [12], electronics [3], and environmental [13] fields. Among the different structural form of carbon, carbon fibers (CF) and carbon nanofibers (CNF) are quite attractive due to their easy fabrication and controllable

Address correspondence to E-mail: bhushanpatil25@gmail.com; tu46@cornell.edu 
properties [14]. CF are commonly produced from polymeric precursor such as polyacrylonitrile (PAN) fibers [15] yet the use of more economical synthetic precursor such as polyethylene fibers [16] is also possible. CF can also be produced from bio-based precursors such as regenerated cellulose fibers (i.e., rayon) and lignin-based fibers [17, 18]. Similar to CF, $\mathrm{CNF}$ are produced by pyrolysis of precursor nanofibers in which nanofibers are typically obtained by electrospinning technique or some other nanofiber production techniques. The electrospinning is a versatile fiber production technique to produce ultrafine fibers (nanofibers) having fiber diameter less than one micron [19]. Electrospun nanofibers obtained from a variety of different materials such as PAN [20], polyvinylidene fluoride (PVDF) [21], polymer of intrinsic porosity (PIM-1) [22], and lignin [23] have been used as precursors for the production of CNF [24]. In most cases, toxic organic solvents are used for the electrospinning of fibers; for instance, dimethylformamide (DMF) is used for the synthesis of electrospun PAN fibers. There is a growing interest to use bio-based materials into suitable precursor fibers for the production of CF and CNF [18, 25]. In this study, we aimed to produce CNF from electrospun cyclodextrin nanofibers. This is also a green approach since water is used as a solvent for the electrospinning of cyclodextrin nanofibers.

Cyclodextrins (CD) are bio-based molecules formed by the enzymatic modification of starch which are categorized as cyclic oligosaccharides. The native cyclodextrins are mainly named as $\alpha$-CD (6 units), $\beta-\mathrm{CD}$ ( 7 units), and $\gamma-\mathrm{CD}$ (8 units) based on the number of $\alpha$-D-glucopyranoside units linked by $\alpha-1,4-$ glycosidic bonds in a ring shape [26]. Besides these native cyclodextrins, chemically modified cyclodextrins such as hydroxyl propylated $\mathrm{CD}$, methylated $C D$, and sulfobutylated $C D$ are also available in which these modified cyclodextrins are more hydrophilic in nature and therefore highly water soluble [27]. CD molecules form aggregates in their concentrated solutions due to intermolecular hydrogen bonding, and the presence of such aggregates facilitates the electrospinning of nanofibers from $\mathrm{CD}$ solutions [28]. Even though the electrospinning of nanofibers from cyclodextrins is much more challenging than electrospinning of nanofibers from polymeric materials since cyclodextrins are small molecules, electrospinning of nanofibers from chemically modified CD molecules (i.e., hydroxypropylated CD [29-31], methylated CD [30, 32], and sulfobutylated CD [33-35]) is relatively easy compared to native $C D$ molecules (i.e., $\alpha-C D$ $[36,37], \beta-C D$ [36-38], and $\gamma-C D[36,39])$.

Being cyclic oligosaccharides, CD molecules can be used precursor for carbon materials [40]. Thermal decomposition of $\mathrm{CD}$ molecules leads to char or pyran and furan production similar to cellulose [41]. The typical thermal decomposition of CD molecules involves two steps; at low temperature, char is produced by glycosidic-bond cleavage with chain-end mechanism, and after that, pyran and furan are produced mainly by transglycosylation and glycolysis process via intra-chain cleavage at higher temperatures [42]. Thus, maintaining the structure during the pyrolysis is a great challenge for CD-based carbon products. In addition to pyrolysis, chemical decomposition of $\mathrm{CD}$ has been reported by the dehydration; however, this chemical acidic treatment destroys the CD structure while producing carbon [40]. On the other hand, pyrolysis of CD-based nanosponges where the $C D$ molecules were hyper cross-linked with the pyromellitic dianhydride resulted in hollow spheres of microporous carbon, whereas CD crosslinked with hexamethylene diisocyanate was ineffective to produce microporous carbon demonstrating that the cross-linker drastically influences the carbon properties particularly surface area and porosity of the CD-based carbons [43]. It has also been reported that microfibers of microporous carbon could be obtained by pyrolysis from electrospun fibrous nanosponges of cyclodextrin polymer crosslinked with pyromellitic dianhydride [44]. Yet, to the best of our knowledge, there has been no study reported related to the use of electrospun polymerfree pure cyclodextrin nanofibers as a precursor for obtaining the carbon nanofibers. Thus, in the present study, pure CD electrospun nanofibers were used as the precursor for the production CNF. Hydroxypropyl- $\beta$-cyclodextrin (HP $\beta C D$ ) nanofibers were successfully produced in the form of self-standing nanofibrous nonwoven mat without the polymeric support or cross-linker by electrospinning [30]. Furthermore, to overcome complete char formation or total decomposition of $\mathrm{CD}$ and to maintain fibrous structure of electrospun HP $\beta C D$ nanofibers, we have optimized combination of chemical and thermal treatment to obtain CD-based CNF. The novelty of the present study is the carbonization of electrospun polymer-free HP $\beta C D$ nanofibers by the dehydration 
(chemical treatment) and pyrolysis (thermal treatment) in order to obtain CNF.

\section{Experimental}

\section{Electrospinning of HPßCD nanofibers}

The electrospinning of pristine HP $\beta C D$ nanofibers without using any carrier polymeric matrix was performed according to our previous study [30]. A highly concentrated aqueous solution of HP $\beta C D$ $\left(\right.$ Cavasol $^{\circledR}$ W7 HP, kindly given by Wacker Chemie AG, Germany) at a concentration of $200 \%$, w/v (2 g of $\mathrm{HP} \beta C D$ in $1 \mathrm{~mL}$ solvent) was prepared in water (Millipore Milli-Q). After that, the electrospinning of the $200 \%(\mathrm{w} / \mathrm{v})$ HP $\beta C D$ aqueous solution was performed in order to produce HP $\beta C D$ nanofibers. For the electrospinning of the HP $\beta C D$ nanofibers, the $200 \%(\mathrm{w} / \mathrm{v})$ HP $\beta C D$ aqueous solution was loaded into $1 \mathrm{~mL}$ plastic syringe with a 27-gauge metallic needle. Then, the syringe loaded with $200 \%$ (w/v) $\mathrm{HP} \beta C D$ aqueous solution was placed on a syringe pump (KD Scientific, KDS-101, USA), and the flow rate of $0.5 \mathrm{~mL} \mathrm{~h}^{-1}$ was set for the HP $\beta C D$ solution. The electrospinning was performed at a high voltage of $15 \mathrm{kV}$ by using high voltage-power supply (AU Series, Matsusada Precision Inc., Japan). The distance between the stationary grounded metal collector covered with aluminum foil and the tip of the needle was adjusted as $\sim 15 \mathrm{~cm}$. The electrospun HP $\beta C D$ nanofibers were deposited on the collector in the form of a nonwoven mat. The electrospinning was carried out in an enclosed Plexiglas box at $25{ }^{\circ} \mathrm{C}$ and $30 \%$ relative humidity.

\section{Carbonization}

The carbonization of electrospun HP $\beta C D$ nanofibrous mat was carried out in two ways: first by chemical dehydration and second by the combination of chemical and thermal (pyrolysis) treatments. Prior to carbonization, the electrospun $\mathrm{HP} \beta C D$ nanofibrous mat was vacuum dried at $120{ }^{\circ} \mathrm{C}$ for $24 \mathrm{~h}$.

First method: chemical dehydration of electrospun $H P \beta C D$ nanofibers

The electrospun HP $\beta C D$ nanofibers were chemically dehydrated by slightly altering the procedure reported for the synthesis of carbon from the $\beta-C D$ [40]. Unlike reported acid concentration (i.e., $0.6 \mathrm{M}$ $\mathrm{H}_{2} \mathrm{SO}_{4}$ ), the concentration of $\mathrm{H}_{2} \mathrm{SO}_{4}$ was reduced to $0.6 \mathrm{mM}$ to avoid complete dehydration of $\mathrm{HP} \beta \mathrm{CD}$ nanofibers. In the flask, totally $30 \mathrm{~mL}$ solution of $0.6 \mathrm{mM} \mathrm{H}_{2} \mathrm{SO}_{4}$ (Sigma-Aldrich, 99.9\%) was prepared in the toluene (Sigma-Aldrich, anhydrous 99.8\%). About $33 \mathrm{mg}$ of $\mathrm{HP} \beta C D$ nanofibrous mat was immersed in the flask containing $0.6 \mathrm{mM} \mathrm{H}_{2} \mathrm{SO}_{4}$ and fixed it with the reflux system. The system was refluxed at $110{ }^{\circ} \mathrm{C}$ for $24 \mathrm{~h}$, and the stirring of the solution was circumvented to avoid the damage of the HP $\beta C D$ nanofibrous mat by mechanical forces. The HP $\beta C D$ nanofibrous mat slowly turns yellow after approximately 10-h reflux and then finally becomes black after 24-h reflux. An excess solution was decanted from the flask leaving behind the wet $\mathrm{CNF}$. The wet CNF were further dried by the rotary evaporator to remove the remaining solvent. After that, the chemically dehydrated HP $\beta C D$ nanofibrous mat was thoroughly washed with the deionized water. The untreated HP $\beta C D$ nanofibers can be rapidly dissolved in the water and washed away during this step leaving behind the chemically treated carbon nanofibers. The CNF obtained from the chemical dehydration process of HP $\beta C D$ nanofibers by using $0.6 \mathrm{mM} \mathrm{H}_{2} \mathrm{SO}_{4}$ were dried at $120{ }^{\circ} \mathrm{C}$ for $24 \mathrm{~h}$ and noted as chemically carbonized nanofibers (CCCD-NF).

Second method: partial chemical dehydration and pyrolysis of electrospun HP $\beta C D$ nanofibers

Chemical dehydration process was limited by reducing the acid concentration to obtain partially dehydrated HP $\beta C D$ nanofibers. The procedure of chemical dehydration mentioned above was repeated by using $10 \mu \mathrm{M} \mathrm{H}_{2} \mathrm{SO}_{4}$ and refluxed for approximately $72 \mathrm{~h}$ instead of $24 \mathrm{~h}$ followed by washing with water to remove the residues of untreated fibers and dried at $120{ }^{\circ} \mathrm{C}$ for $24 \mathrm{~h}$. The light yellowish-gray colored nanofibrous mat with approximately $20 \%$ of initial fibers was obtained which is referred as partially chemical carbonized HP $\beta C D$ nanofibers (PCCCD-NF). The PCC-CD-NF mat was placed inside the tubular furnace (Thermcraft, model number: XST 3-018-1V) and pyrolyzed at $800{ }^{\circ} \mathrm{C}$ for $3 \mathrm{~h}$ with the $5{ }^{\circ} \mathrm{C} \mathrm{min}{ }^{-1}$ under argon flow at the rate of $100 \mathrm{sccm}$. Prior to heating, an argon gas was purged inside the furnace tube to replace air with inert argon 
atmosphere for $45 \mathrm{~min}$. The CNF synthesized after pyrolysis were referred as carbonized nanofibers based on HP $\beta C D$ nanofibers (C-CD-NF).

\section{Characterization}

The scanning electron microscopy (SEM, FEI Quanta 200 FEG, $10 \mathrm{kV}$ ) was used for the morphological investigation of the samples. Prior to SEM imaging, the samples were sputtered with gold $(\sim 10 \mathrm{~nm})$ in order to eliminate the possible charging. An average of 50 fibers diameter was used for estimating the distribution of the nanofiber diameters by the ImageJ software. X-ray photoelectron spectrometer (XPS, Thermo K-alpha) was used for gathering the information from the samples on the chemical bonding by the survey (2 scans) and high resolution (50 scans; pass energy, $30 \mathrm{eV}$, step size, $0.1 \mathrm{eV}$ and spot size $400 \mu \mathrm{m})$. The presence of crystalline and/or amorphous state of the samples was investigated by PANalytical X-ray powder diffractometer [XRD, $\mathrm{CuK} \alpha$ radiation $(\lambda=1.54 \AA)$ ]. The surface area and pore size distribution of samples were analyzed from $\mathrm{N}_{2}$ adsorption isotherms (77 K) at a relative pressure of 0.995 using multi-point analysis [Brunauer-Emmet-Teller (BET), Quantachrome AutosorbiQ gas sorption analyzer]. The total pore volume and average radius diameter were calculated by the density functional theory (DFT) method. Before $\mathrm{N}_{2}$ adsorption isotherms, the samples were degassed at $120{ }^{\circ} \mathrm{C}$ for $12 \mathrm{~h}$ under high vacuum. The Raman spectra for the samples were recorded by WITec alpha 300 confocal Raman at 3 different spots.

\section{Results and discussion}

An effect of chemical and thermal treatment on the morphology of HP $\beta C D$ nanofibers was studied by SEM images (Fig. 1a-e). The chemical treatment on the HP $\beta C D$ nanofibers (Fig. 1a, b) with the $0.6 \mathrm{mM}$ $\mathrm{H}_{2} \mathrm{SO}_{4}$ concentration affects their fiber morphology and forms the $\mathrm{CNF}$ with fused structure. However, after reducing the $\mathrm{H}_{2} \mathrm{SO}_{4}$ concentration from $0.6 \mathrm{mM}$ to $10 \mu \mathrm{M}$ during the chemical treatment of $\mathrm{HP} \beta C \mathrm{CD}$ nanofibers, it clearly shows that the fiber structure remains intact with noticeable diameter reduction from $1.19 \pm 0.33 \mu \mathrm{m} \quad(\mathrm{HP} \beta C D$, inset Fig. 1a1) to $650 \pm 150 \mathrm{~nm}$ (PCC-CD-NF, inset Fig. 1c1). Thus, it is proving the importance of the $\mathrm{H}_{2} \mathrm{SO}_{4}$ concentration used in the chemical treatment on the morphology of nanofibers. It is expected because the rate of dehydration in the HP $\beta C D$ nanofibers depends on the $\mathrm{H}_{2} \mathrm{SO}_{4}$ concentration. The $0.6 \mathrm{mM} \mathrm{H}_{2} \mathrm{SO}_{4}$ chemical treatment can deform the chemical structure of $\mathrm{HP} \beta C D$ during the process of dehydration, and partial dissolution of HP $\beta C D$ nanofibers results in the fused nanofibrous structure (Fig. 1b). When the concentration of $\mathrm{H}_{2} \mathrm{SO}_{4}$ is reduced to $10 \mu \mathrm{M}$, partial decomposition of the top layer of HP $\beta C D$ nanofibers reduces the diameter of nanofibers, keeping its fibrous structure intact. These PCC-CD-NF after pyrolysis further reduce the nanofiber diameters with the unbroken nanofiber structure which results in the $\mathrm{CNF}$ having an average diameter of $380 \pm 150 \mathrm{~nm}$ (C-CD-NF, inset Fig. 1d1). Unlike CC-CD-NF, the fused nanofibrous structure was not observed in the PCC-CD-NF. To confirm the importance of partial chemical treatment in the CNF formation, the pyrolysis of HP $\beta C D$ nanofibers was carried out excluding the chemical treatment which results in the total decomposition of fibrous morphology with the formation of char (Fig. 1e). This result of char formation by the direct pyrolysis of $\mathrm{HP} \beta C D$ nanofibers is in good agreement with the previous report on the thermal decomposition of CD [42].

The degree of carbon formation was determined by the Raman spectra (Fig. 2a). The Raman spectrum of HP $\beta C D$ nanofibers is presented in Fig. 2a (red line). The peaks at ca. $430 \mathrm{~cm}^{-1}$ (the skeletal modes of $\alpha-1,4$ linkage), 800 to $1500 \mathrm{~cm}^{-1}, 3000 \mathrm{~cm}^{-1}(\mathrm{CH}$ stretching of hydroxypropyl group), and $3100-3600 \mathrm{~cm}^{-1}$ (OH stretching) resemble with the HP $\beta C D$ Raman spectra reported earlier $[45,46]$. The emergence of new graphitic carbon peak ( $\mathrm{G}$ bands at $1580 \mathrm{~cm}^{-1}$ ) in addition to the disordered carbon peak ( $\mathrm{D}$ band at $1330 \mathrm{~cm}^{-1}$ ) validates the conversion of $\mathrm{HP} \beta C D$ nanofibers into the carbon of the CC-CD-NF (Fig. 2a, blue spectrum) and C-CD-NF (Fig. 2a, black spectrum). Furthermore, an absence of Raman bands of $\mathrm{HP} \beta C D$ nanofibers (at ca. $430 \mathrm{~cm}^{-1}, 800$ to $1500 \mathrm{~cm}^{-1}, 3000 \mathrm{~cm}^{-1}$, and $3100-3600 \mathrm{~cm}^{-1}$ ) in the CC-CD-NF and C-CD-NF verifies total carbonization of HP $\beta C D$ nanofibers. The Raman bands observed in the HP $\beta C D$ nanofibers are also present in the PCCCD-NF (with reduced peak intensities) proving that HP $\beta C D$ nanofibers were partially decomposed and not dehydrated like CC-CD-NF [40]. In addition, the presence of humps at the $G$ band along with the peaks of $H P \beta C D$ nanofibers substantiates the partial 
Figure 1 Representative SEM images of a HP $\beta C D$ nanofibers, $\mathbf{b}$ CC-CD-NF, c PCC-CD-NF, d C-CD-NF, and e char, at the low magnification (1) and high magnification (2). The average nanofiber diameter distribution plotted in the insets for a1 HP $\beta C D$ nanofibers, c1 PCCCD-NF, and d1 C-CD-NF.
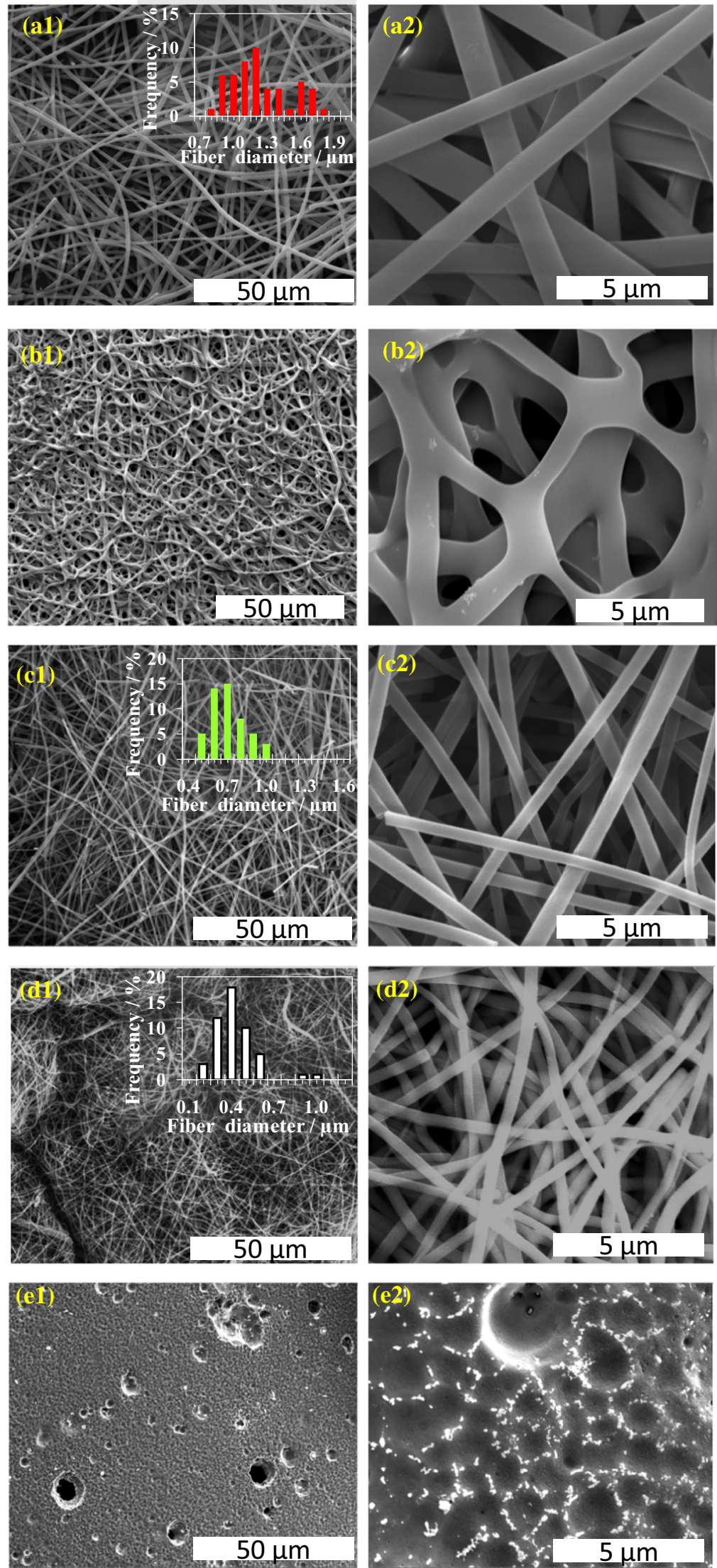

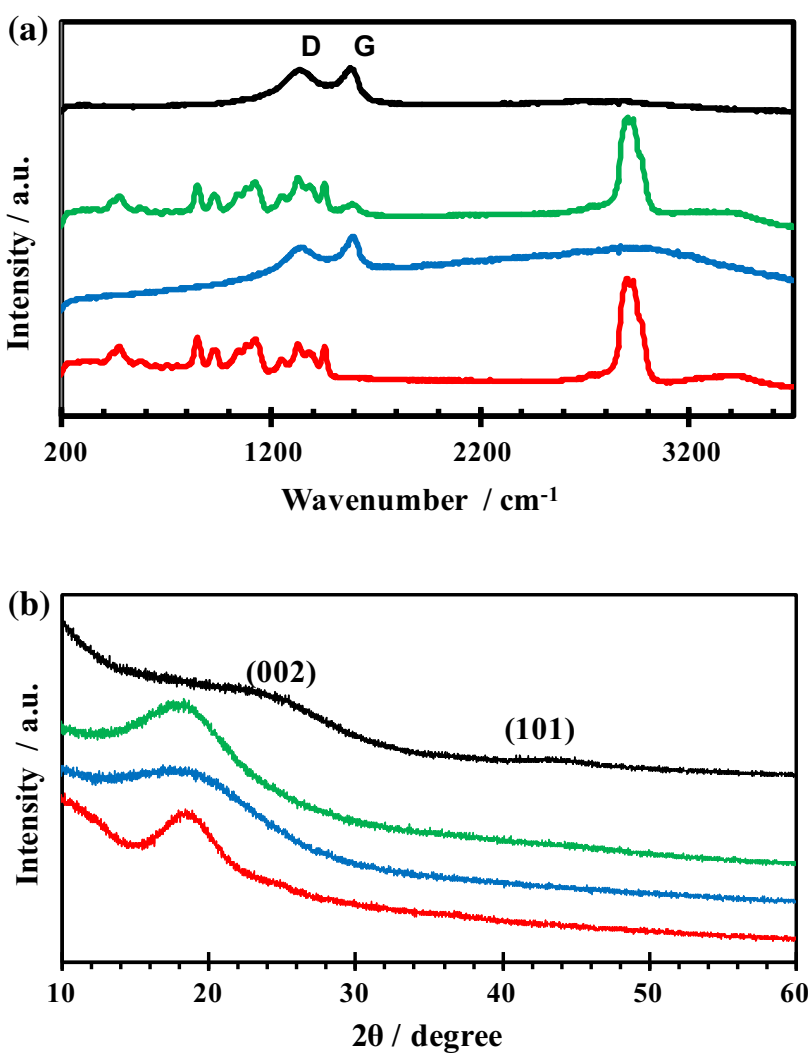

Figure 2 a Raman and $\mathbf{b}$ XRD spectra of $\mathrm{HP} \beta C D$ nanofibers (red line), CC-CD-NF (blue line), PCC-CD-NF (green line), and C-CD-NF (black line).

carbonization (Fig. 2a, green line). This $\mathrm{G}$ band is absent in the HP $\beta C D$ nanofibers while the intensity of this peak increased in the order of PCC-CD$\mathrm{NF}<\mathrm{CC}-\mathrm{CD}-\mathrm{NF}=\mathrm{C}-\mathrm{CD}-\mathrm{NF}$. Thus, we can conclude that chemical treatment with $10 \mu \mathrm{M} \mathrm{H}_{2} \mathrm{SO}_{4}$ initiates graphitic carbon formation which increases by increasing its concentration. Furthermore, upon pyrolysis of PCC-CD-NF, Raman bands of HP $\beta C D$ nanofibers disappear and only $D$ and $G$ bands remained in the C-CD-NF. It is worth to focus on the intensities of the $\mathrm{OH}$ stretching peak $\left(3100-3600 \mathrm{~cm}^{-1}\right)$ in these Raman spectra for HP $\beta C D$ nanofiber, CC-CD-NF, PCC-CD-NF, and C-CD-NF which has the trend HP $\beta C D$ nanofibers $>$ PCC-CD$\mathrm{NF}>\mathrm{CC}-\mathrm{CD}-\mathrm{NF}>\mathrm{C}-\mathrm{CD}-\mathrm{NF}$ (almost negligible). It also proves that $\mathrm{OH}$ groups are removed from the HP $\beta C D$ nanofiber surface by the chemical as well as pyrolysis process by the dehydration. The $I_{\mathrm{D}}: I_{\mathrm{G}}$ ratios of the D and G peak intensities for CC-CD-NF and C-CD-NF are 0.84 and 0.97 , respectively. Since the G band intensities were almost identical in the CC-CD$\mathrm{NF}$ and C-CD-NF, the difference in the $I_{\mathrm{D}}: I_{\mathrm{G}}$ ratio was due to the increase in the disordered carbon during the pyrolysis. Another possibility of intense $G$ band than the D band in the CC-CD-NF can be related to the lowest size of graphitic plane basal dimension [40, 47].

The crystal structure analyses were performed by $\mathrm{XRD}$, and the diffraction patterns of the samples are plotted in Fig. 2b. As per the earlier studies, HP $\beta C D$ nanofibers (Fig. 2b, red spectrum) are amorphous having a very broad halo diffraction pattern centered at $2 \theta=19^{\circ}$ [45]. After chemical treatment with the $0.6 \mathrm{mM} \mathrm{H}_{2} \mathrm{SO}_{4}$, CC-CD-NF (Fig. 2b, blue spectrum) have broadened this peak as a result of the sum of $\mathrm{HP} \beta C D$ nanofibers amorphous peak and turbostratic carbon ( $2 \theta \sim 26^{\circ}, 002$ plane). Furthermore, an absence of a peak at $2 \theta \sim 43^{\circ}$ (101 plane) proved the low value of graphitic plane basal dimension which is in agreement with the Raman spectra, authenticating the amorphous nature of the CC-CD-NF. XRD pattern of PCC-CD-NF (Fig. 2b, green spectrum) has $2 \theta \sim 19^{\circ}$; however, full width half maxima (FWHM) value is higher than HP $\beta C D$ nanofibers. This broadening of the peak can be referred to the degree of increase in the amorphous nature of PCC-CD-NF than the pristine HP $\beta C D$ nanofibers. The C-CD-NF (Fig. 2b, black spectrum) clearly present two broad peaks at $2 \theta \sim 26^{\circ}$ and $\sim 43^{\circ}$ corresponding to 002 and 10 planes of the turbostratic carbon which is further evidence of carbonization of $\mathrm{HP} \beta C D$ nanofibers.

The chemical compositions and atomic binding energies of carbon and oxygen for the nanofibers were analyzed by the XPS (Fig. 3). The atomic percentage of carbon and oxygen in the HP $\beta C D$ nanofibers (Fig. 3a1), PCC-CD-NF (Fig. 3b1), CC-CD-NF (Fig. 3c1), and C-CD-NF (Fig. 3d1) were C: $62.6 \%$ O: $37.4 \%$; C: $63.2 \%$ O: $36.8 \%$; C: $75 \%$ O: $25 \%$; and C: $94.2 \%$ O: $5.8 \%$, respectively. The decrease in the oxygen atomic percentage in the PCC-CD-NF and CC-CD-NF can be assigned to loss of oxygen during the dehydration of HP $\beta C D$ nanofibers (mainly from the $\mathrm{OH}$ group) by the chemical treatment. As the concentration of $\mathrm{H}_{2} \mathrm{SO}_{4}$ was increased from $10 \mu \mathrm{M}$ to $0.6 \mathrm{mM}$, oxygen percent decreases from 33.6 to $25 \%$. The pyrolysis of PCC-CD-NF may remove amorphous carbon, $\mathrm{CO}$ and $\mathrm{CO}_{2}$ (generated during the pyrolysis) which further reduced the oxygen content in the C-CD-NF than the PCC-CD-NF. The removal of these functional groups results in the reduced diameter of C-CD-NF than the PCC-CD-NF and the 

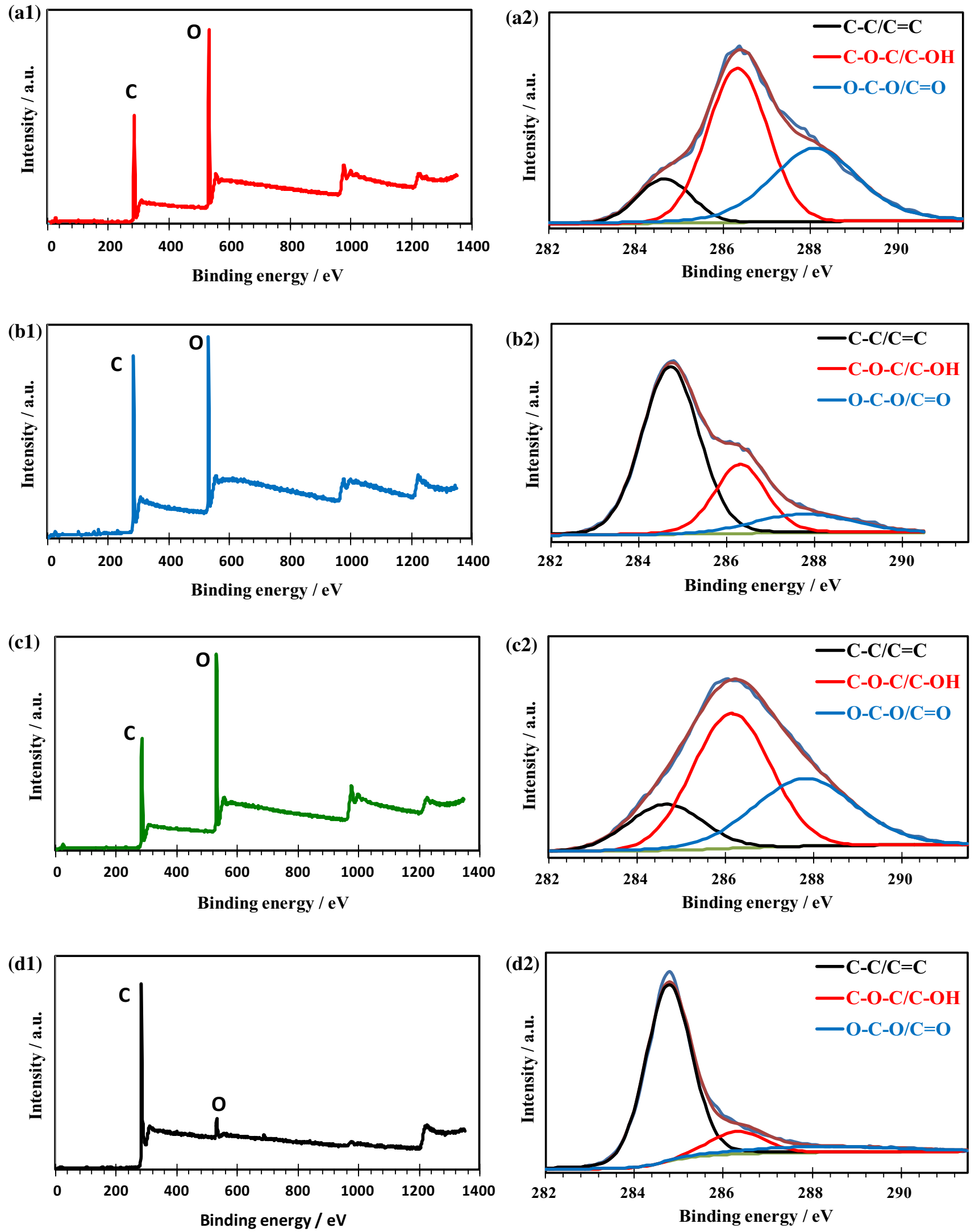

Figure 3 (1) XPS survey and (2) high-resolution carbon XPS of a HP $\beta C D$ nanofibers, b CC-CD-NF, c PCC-CD-NF, and d C-CD-NF. 
HP $\beta C D$ nanofibers. According to the reported carbon and oxygen binding energies, the high-resolution carbon spectra of HP $\beta C D$ nanofibers, PCC-CD-NF, CC-CD-NF, and C-CD-NF were deconvoluted into three major peaks at the 284.8, 286.2, and $288.0 \pm 0.2 \mathrm{eV}$ corresponding to $\mathrm{C}-\mathrm{C} / \mathrm{C}=\mathrm{C}, \mathrm{C}-\mathrm{O}-\mathrm{C} /$ $\mathrm{C}-\mathrm{OH}$, and $\mathrm{O}-\mathrm{C}-\mathrm{O} / \mathrm{C}=\mathrm{O}$ (Fig. 3a2-d2) [48, 49]. To reveal an effect of the decomposition process of the $\mathrm{HP} \beta C D$ nanofibers, the ratio of carbon (i.e., $\mathrm{C}-\mathrm{C} /$ $\mathrm{C}=\mathrm{C}$ ) to the oxidized carbon (i.e., $\mathrm{C}-\mathrm{O}-\mathrm{C} / \mathrm{C}-\mathrm{OH}$ and $\mathrm{O}-\mathrm{C}-\mathrm{O} / \mathrm{C}=\mathrm{O}$ ) is estimated. It follows the order of HP $\beta C D$ nanofibers < PCC-CD-NF < CC-CD-NF < C-CD-NF. It shows that the carbon percentage in the CC-CD-NF has increased as the concentration of the $\mathrm{H}_{2} \mathrm{SO}_{4}$ increased (from $10 \mu \mathrm{M}$ to $0.6 \mathrm{mM}$ ). Furthermore, pyrolysis process has further removed the oxidized carbon in the C-CD-NF than the chemically dehydrated PCC-CD-NF and CC-CD-NF.

The BET analysis (Fig. 4) indicates the $\mathrm{N}_{2}$ adsorption and desorption curve which follows the type IV isotherm. The DFT (slit pore, NLDFT equilibrium model, at relative pressure $P / \mathrm{Po}=0.995)$ is used for the pore volume and diameter measurements (Fig. 4,
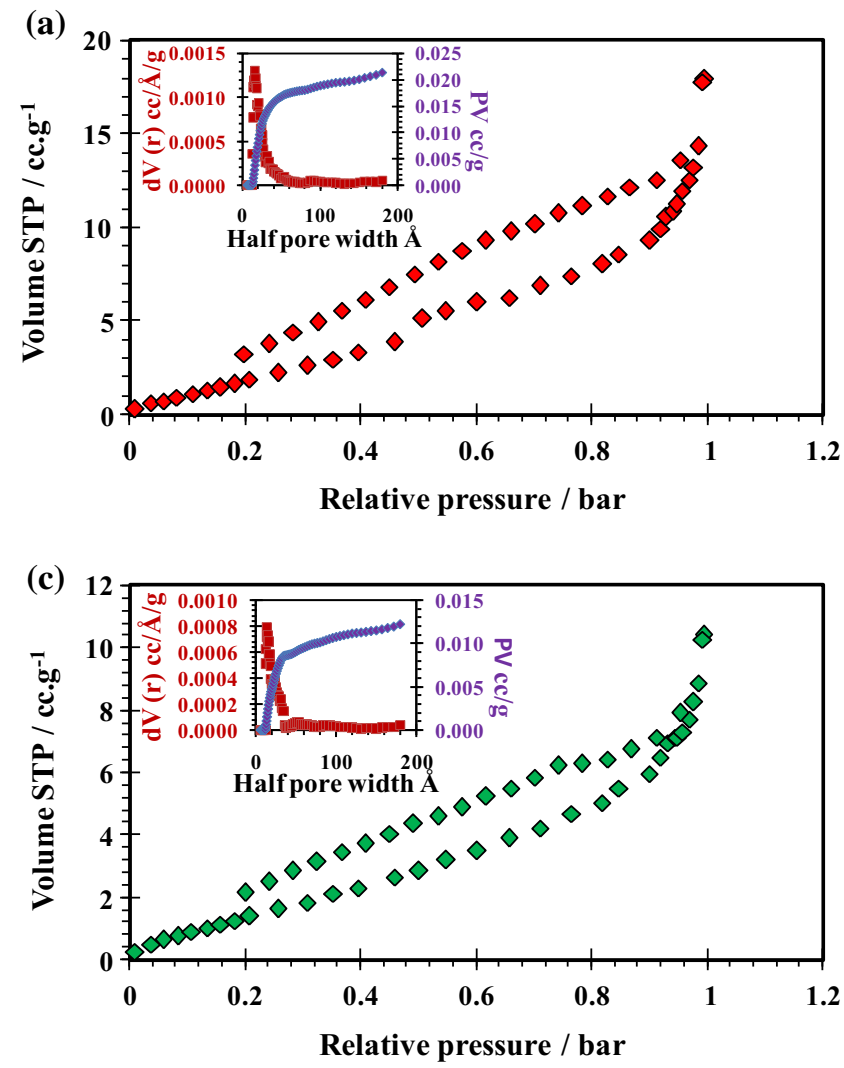

insets). The total surface area, total pore volume, and average pore diameter of HP $\beta C D$ nanofibers, $C C-C D$ $\mathrm{NF}$, PCC-CD-NF, and C-CD-NF are summarized in Table 1. The surface area of HP $\beta C D$ nanofibers reduced according to the concentration of $\mathrm{H}_{2} \mathrm{SO}_{4}$ used in the chemical treatment. It is expected due to the blocking of pores as a result of dehydration [40]. Furthermore, the pores in the CC-CD-NF and C-CD$\mathrm{NF}$ were mesopores with the surface area of $5.9 \mathrm{~m}^{2} \mathrm{~g}^{-1}$ and $52.5 \mathrm{~m}^{2} \mathrm{~g}^{-1}$, respectively. Pyrolysis of PCC-CD-NF might have open the blocked pores formed during the dehydration as well as the consequence of some thermal decomposition of PCCCD-NF which can increase the surface area of C-CDNF.

The surface area of C-CD-NF is close to the carbon fibers $\left(\sim 60 \mathrm{~m}^{2} \mathrm{~g}^{-1}\right)$ obtained from PAN fibers. In addition, turbostratic nature of C-CD-NF creates more edges or in other words defects which can be beneficial in deposition of numerous nanoparticles for catalytic purpose also for the gas storage like hydrogen [50]. Thus, C-CD-NF can be useful as a support in catalytic reactions like oxygen reduction,
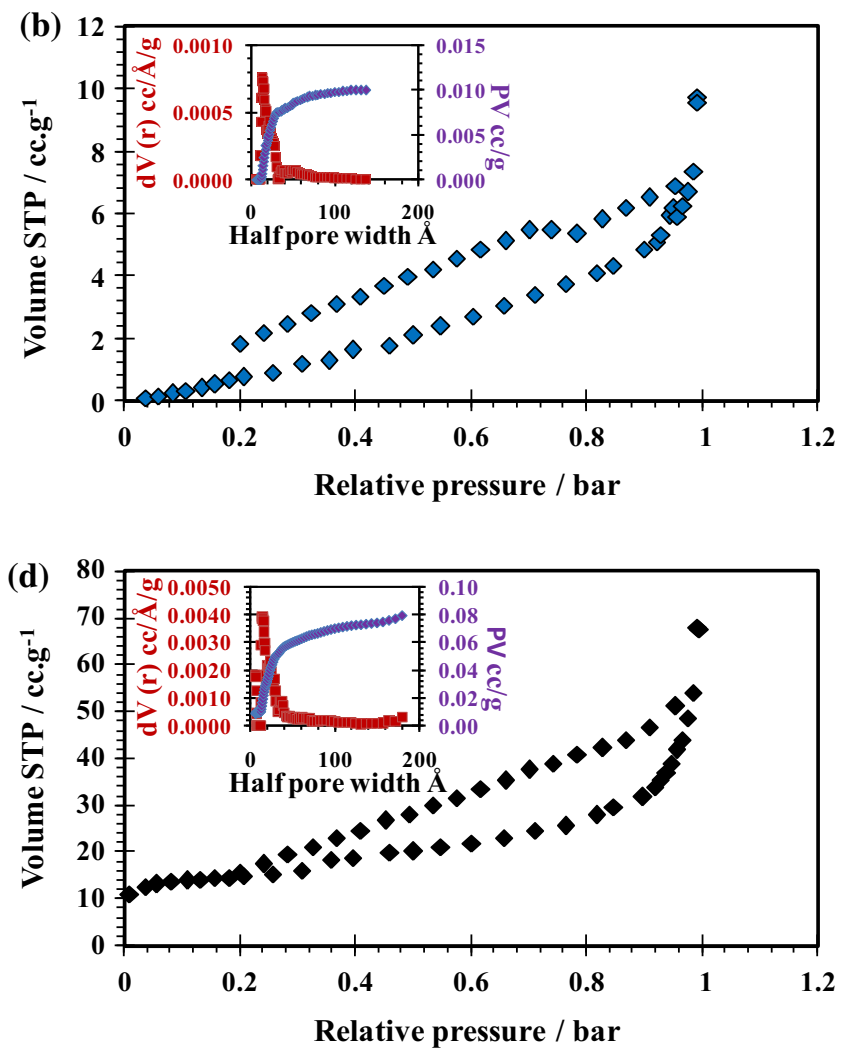

Figure $4 \mathrm{~N}_{2}$ adsorption-desorption plots obtained for a HP $\beta C D$ nanofibers, $\mathbf{b}$ CC-CD-NF, $\mathbf{c}$ PCC-CD-NF, and d C-CD-NF. The inset shows the DFT plots for the cumulative pore volume (PV) and $\mathrm{d} V$ with respect to half pore width for the respective samples. 
Table 1 Porosity characteristics of $\mathrm{HP} \beta C D$ nanofibers, CC-CD-NF, PCC$\mathrm{CD}-\mathrm{NF}$, and C-CD-NF

\begin{tabular}{lcll}
\hline Sample & Surface area $\left(\mathrm{m}^{2} \mathrm{~g}^{-1}\right)$ & Pore volume $\left(\mathrm{cm}^{3} \mathrm{~g}^{-1}\right)$ & Pore radius $(\AA)$ \\
\hline HP $\beta C D$ nanofibers & 8.6 & 0.027 & 64 \\
CC-CD-NF & 5.9 & 0.014 & 49 \\
PCC-CD-NF & 6.7 & 0.016 & 48 \\
C-CD-NF & 52.5 & 0.104 & 39 \\
\hline
\end{tabular}

Figure 5 Schematic representation of $\mathrm{C}-\mathrm{CD}-\mathrm{NF}$ formation from the electrospun HP $\beta C D$ nanofibers.

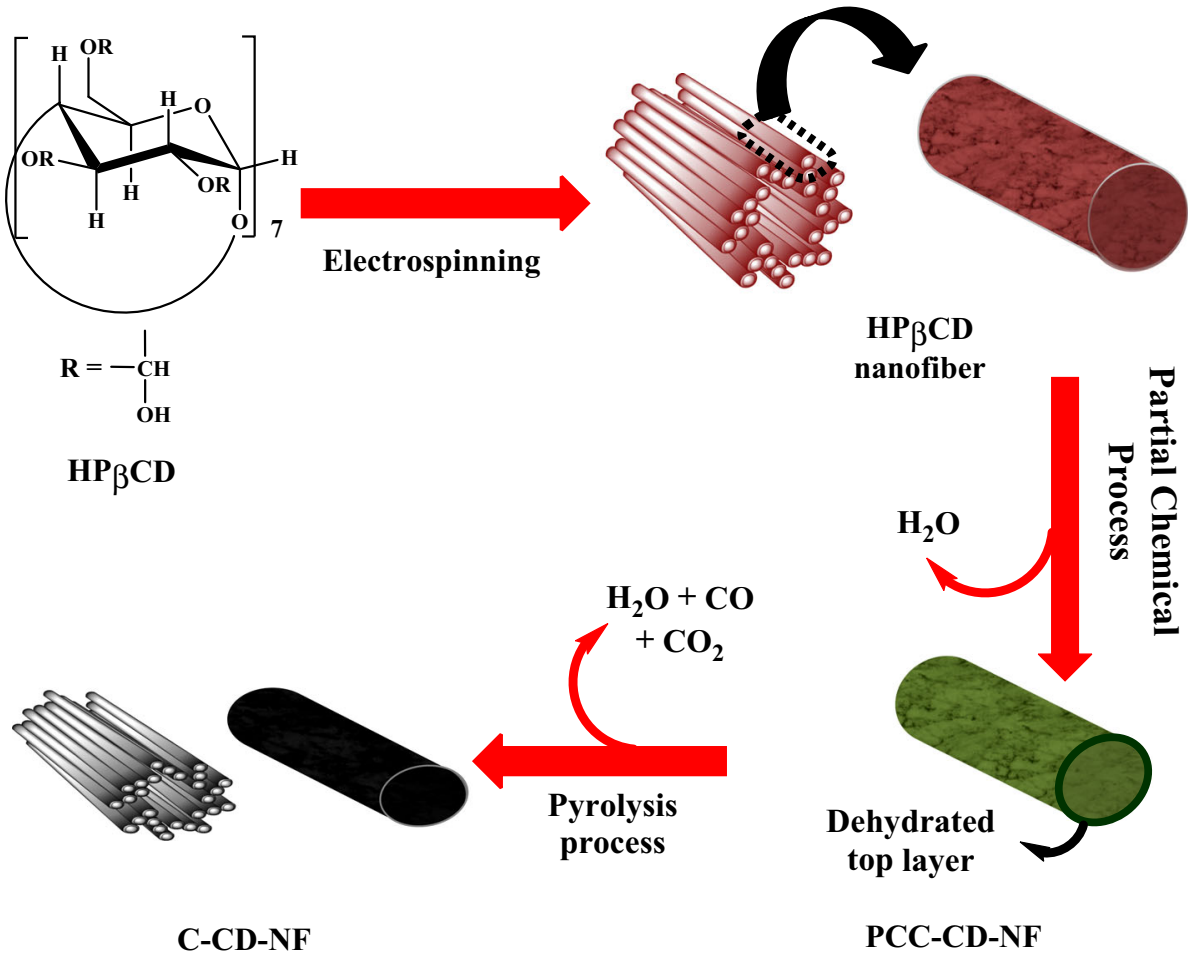

water splitting, energy storage material, hydrogen storage, sensors and it can be also useful for water filtration to remove toxic elements $[13,20]$.

\section{Proposed mechanism of CNF synthesis from the electrospun HP $\beta C D$ nanofibers}

Due to the presence of the Raman bands of HP $\beta C D$ nanofibers and carbon in the PCC-CD-NF (i.e., $10 \mu \mathrm{M}$ $\mathrm{H}_{2} \mathrm{SO}_{4}$ treated electrospun HP $\beta C D$ nanofibers), it is clear that it produced a partially dehydrated layer on top of the HP $\beta C D$ nanofibers. These results were further confirmed by the slight decrease in the oxygen content of the PCC-CD-NF (33.6\%) than the $\mathrm{HP} \beta C D$ nanofibers (37.4\%). The electrospun HP $\beta C D$ nanofibers are water soluble while PCC-CD-NF become insoluble due to surface dehydration. Thus, we predict that partial dehydration by low concentrated acid treatment $\left(10 \mu \mathrm{M} \mathrm{H}_{2} \mathrm{SO}_{4}\right.$ ) forms the thin coating of hydrophobic layers on the HP $\beta C D$ nanofibers by removal of some hydroxyl groups. On the contrary, a high concentration of $\mathrm{H}_{2} \mathrm{SO}_{4}$ treatment $(0.6 \mathrm{mM})$ on the electrospun $\mathrm{HP} \beta C D$ nanofibers results in more dehydration than PCC-CD-NF. Furthermore, chances of partial dissolution of some $\mathrm{HP} \beta C D$ nanofibers might be possible in the presence of high acid concentration which results in the fused CC-CD-NF.

The $\mathrm{OH}$ group in the $\mathrm{CD}$ plays a vital role during the thermal decomposition process by dehydration through depolymerization and cross-linking. Thus, replacing it by attaching another polymer or other functional groups like the tosyl group has been tried [41]. Selection of proper replacement is required to change the thermal decomposition of $\mathrm{CD}$; therefore, as reported earlier, tosyl group can increase the CDF decomposition while amino groups do not show any 
significant change [41]. Any functional group which makes hydrogen bond may lead to such decomposition [41, 43]. Therefore, partial chemical treatment to reduce the $\mathrm{OH}$ groups is an important step for successful retaining fibrous morphology during the pyrolysis. The importance of this step is further validated by the pyrolysis of electrospun HP $\beta C D$ nanofibers which results in the char formation with the total destruction of fibrous morphology. The $\mathrm{OH}$ group or formation of water during the pyrolysis of electrospun HP $\beta C D$ nanofibers (i.e., without chemical treatment) may easily oxidize the carbon to form $\mathrm{CO}$ and $\mathrm{CO}_{2}$ at elevated temperature which results in the total destruction of nanofibers [51, 52]. Thus, the overall mechanism of CNF formation from the electrospun HPßCD nanofibers by the combination of partial chemical and pyrolysis process is proposed in Fig. 5.

\section{Conclusions}

The electrospun polymer-free HP $\beta C D$ nanofibers were successfully converted to CNF without breaking the fibrous morphology with the combination of partial chemical dehydration and pyrolysis process. The dehydration of electrospun HP $\beta C D$ nanofibers with the $0.6 \mathrm{mM} \mathrm{H}_{2} \mathrm{SO}_{4}$ leads to fused $\mathrm{CNF}$ while direct pyrolysis results in a char formation. The effect of each treatment on the HP $\beta C D$ nanofiber morphology was analyzed by SEM, which shows that fibrous structure remains intact after the combination of partial chemical and pyrolysis treatment yielding CNF having fiber diameter of $380 \pm 150 \mathrm{~nm}$. Carbon formation in the CC-CD-NF and C-CD-NF is confirmed by the presence of only $D$ and $G$ bands of Raman spectra (with almost negligible peaks of HP $\beta C D$ nanofibers) while PCC-CD-NF has both D and $G$ bands along with the bands of HP $\beta C D$ nanofibers (low intensity). The XRD of HP $\beta C D$ nanofibers $\left(2 \theta \sim 19^{\circ}\right)$ shifts to broad peak at $2 \theta \sim 26^{\circ}$ for CCCD-NF (slight hump) and C-CD-NF, while PCC-CD$\mathrm{NF}$ does show significant change. The chemical composition by XPS shows the percentage of carbon atom in the order of HP $\beta C D$ nanofibers $<$ PCC-CD$\mathrm{NF}<\mathrm{CC}-\mathrm{CD}-\mathrm{NF}<\mathrm{C}-\mathrm{CD}-\mathrm{NF}$ and oxygen atom have the trend of HP $\beta C D$ nanofibers $>$ PCC-CD-NF $>$ CCCD-NF $>$ C-CD-NF. The surface area of C-CD-NF is similar to the carbon fibers obtained from PAN fibers. Therefore, controlled $\mathrm{OH}$ removal from the electrospun polymer-free HP $\beta C D$ nanofibers found to be the crucial process during the CNF synthesis. Reducing the hydroxyl functional groups from the top layer of HP $\beta C D$ nanofibers by the partial dehydration process is found to be the key step for CNF formation based on the electrospun HP $\beta C D$ nanofibers. Although the synthesis process is quite long, fiber structure remains intact after pyrolysis without formation of char; this process can be further useful for the fabrication of novel carbon structures with the inclusion complex of cyclodextrins.

\section{Compliance with ethical standards}

Conflict of interest The authors declare that they have no conflict of interest.

\section{References}

[1] Hirsch A (2010) The era of carbon allotropes. Nat Mater 9:868-871

[2] Sharon M, Mishra N, Patil B, Mewada A, Gurung R, Sharon M (2015) Conversion of polypropylene to two-dimensional graphene, one-dimensional carbon nano tubes and zero-dimensional C-dots, all exhibiting typical $s p^{2}$-hexagonal carbon rings. IET Circuits Devices Syst 9:59-66

[3] Maniecki T, Shtyka O, Mierczynski P, Ciesielski R, Czylkowska A, Leyko J et al (2018) Carbon nanotubes: properties, synthesis, and application. Fibre Chem 50:297-300

[4] Castro Neto AH, Guinea F, Peres NMR, Novoselov KS, Geim AK (2009) The electronic properties of graphene. Rev Mod Phys 81:109-162

[5] Brozena AH, Kim M, Powell LR, Wang Y (2019) Controlling the optical properties of carbon nanotubes with organic colour-centre quantum defects. Rev. Chem, Nat. https://doi. org/10.1038/s41570-019-0103-5

[6] Balandin AA (2011) Thermal properties of graphene and nanostructured carbon materials. Nat Mater 10:569-581

[7] Goze C, Vaccarini L, Henrard L, Bernier P, Hernandez E, Rubio A (1999) Elastic and mechanical properties of carbon nanotubes. Synth Met 103:2500-2501

[8] Candelaria SL, Shao Y, Zhou W, Li X, Xiao J, Zhanget JG et al (2012) Nanostructured carbon for energy storage and conversion. Nano Energy 1:195-220

[9] Pech D, Brunet M, Durou H, Huang P, Mochalin V, Gogotsi $Y$ et al (2010) Ultrahigh-power micrometre-sized supercapacitors based on onion-like carbon. Nat Nanotechnol $5: 651-654$

[10] Qureshi A, Kang WP, Davidson JL, Gurbuz Y (2009) Review on carbon-derived, solid-state, micro and nano 
sensors for electrochemical sensing applications. Diam Relat Mater 18:1401-1420

[11] Yang W, Thordarson P, Gooding JJ, Ringer SP, Braet F (2007) Carbon nanotubes for biological and biomedical applications. Nanotechnology 18:1-12

[12] Street KW, Miyoshi K, Vander Wal RL (2007) Application of carbon based nano-materials to aeronautics and space lubrication. In: Erdemir A, Martin J-M (eds) Superlubricity. Elsevier, Amsterdam, pp 311-340

[13] Mauter MS, Elimelech M (2008) Critical review environmental applications of carbon-based nanomaterials. Am Chem Soc 42:5843-5859

[14] Huang X (2009) Fabrication and properties of carbon fibers. Materials (Basel) 2:2369-2403

[15] Newcomb BA (2016) Processing, structure, and properties of carbon fibers. Compos Part A 91:262-282

[16] Zhang D, Bhat GS (1994) Carbon fibers from polyethylenebased precursors. Mater Manuf Process 9:221-235

[17] Stanzione J, La Scala J (2016) Sustainable polymers and polymer science: dedicated to the life and work of Richard P. Wool. J Appl Polym Sci 133:1-2

[18] Hiremath N, Mays J, Bhat G (2017) Recent developments in carbon fibers and carbon nanotube-based fibers: a review. Polym Rev 57:339-368

[19] Uyar T, Kny E (2017) Electrospun materials for tissue engineering and biomedical applications: research, design and commercialization, Woodhead Publishing Series in Biomaterials, 1st edn. Elsevier, London

[20] Khalily MA, Patil B, Yilmaz E, Uyar T (2019) Atomic layer deposition of $\mathrm{Co}_{3} \mathrm{O}_{4}$ nanocrystals on $\mathrm{N}$-doped electrospun carbon nanofibers for oxygen reduction and oxygen evolution reactions. Nanoscale Adv 1:1224-1231

[21] Yang Y, Centrone A, Chen L, Simeon F, Alan Hatton T, Rutledge GC (2011) Highly porous electrospun polyvinylidene fluoride (PVDF)-based carbon fiber. Carbon 49:3395-3403

[22] Patil B, Satilmis B, Khalily MA, Uyar T (2019) Atomic layer deposition of $\mathrm{NiOOH} / \mathrm{Ni}(\mathrm{OH})_{2}$ on PIM-1-based $\mathrm{N}$-doped carbon nanofibers for electrochemical water splitting in alkaline medium. Chemsuschem 12:1469-1477

[23] Ruiz-Rosas R, Bedia J, Lallave M, Loscertales IG, Barrero A, Rodríguez-Mirasol $\mathrm{J}$ et al (2010) The production of submicron diameter carbon fibers by the electrospinning of lignin. Carbon 48:696-705

[24] Zhang B, Kang F, Tarascon JM, Kim JK (2016) Recent advances in electrospun carbon nanofibers and their application in electrochemical energy storage. Prog Mater Sci 76:319-380

[25] Kumar M, Hietala M, Oksman K (2019) Lignin-based electrospun carbon nanofibers. Front Mater 6:1-6
[26] Szejtli J (1998) Introduction and general overview of cyclodextrin chemistry. Chem Rev 98:1743-1754

[27] Szente L (2002) Highly soluble cyclodextrin derivatives: chemistry, properties, and trends in development. Adv Drug Deliv Rev 36:17-28

[28] Topuz F, Uyar T (2018) Influence of hydrogen-bonding additives on electrospinning of cyclodextrin nanofibers. ACS Omega 3:18311-18322

[29] Manasco JL, Saquing CD, Tang C, Khan SA (2012) Cyclodextrin fibers via polymer-free electrospinning. RSC Adv 2:3778-3784

[30] Celebioglu A, Uyar T (2012) Electrospinning of nanofibers from non-polymeric systems: polymer-free nanofibers from cyclodextrin derivatives. Nanoscale 4:621-631

[31] Celebioglu A, Uyar T (2019) Electrospinning of cyclodextrins: hydroxypropyl-alpha-cyclodextrin nanofibers. J Mater Sci. https://doi.org/10.1007/s10853-019-03983-x

[32] Celebioglu A, Uyar T (2010) Cyclodextrin nanofibers by electrospinning. Chem Commun 46:6903-6905

[33] Vass P, Démuth B, Farkas A, Hirsch E, Szabó E, Nagyi B et al (2019) Continuous alternative to freeze drying: manufacturing of cyclodextrin-based reconstitution powder from aqueous solution using scaled-up electrospinning. J Control Release 298:120-127

[34] Y1ld1z ZI, Uyar T (2019) Fast-dissolving electrospun nanofibrous films of paracetamol/cyclodextrin inclusion complexes. Appl Surf Sci 492:626-633

[35] Yıldız ZI, Celebioglu A, Uyar T (2017) Polymer-free electrospun nanofibers from sulfobutyl ether7-beta-cyclodextrin (SBE7- $\beta-C D)$ inclusion complex with sulfisoxazole fastdissolving and enhanced water-solubility of sulfisoxazole. Int J Pharm 531:550-558

[36] Kida T, Sato S, Yoshida H, Teragaki A, Akashi M (2014) 1,1,1,3,3,3-Hexafluoro-2-propanol (HFIP) as a novel and effective solvent to facilely prepare cyclodextrin-assembled materials. Chem Commun 50:14245-14248

[37] Celebioglu A, Uyar T (2013) Electrospinning of nanofibers from non-polymeric systems: electrospun nanofibers from native cyclodextrins. J Colloid Interface Sci 404:1-7

[38] Ahn Y, Kang Y, Ku M, Yang Y-H, Jung S, Kim H (2013) Preparation of $\beta$-cyclodextrin fiber using electrospinning. RSC Adv 3:14983-14987

[39] Online VA (2013) Electrospun gamma-cyclodextrin $(\gamma-\mathrm{CD})$ nanofibers for the entrapment of volatile organic compounds. RSC Adv 1:22891-22895

[40] Jaouadi M, Hbaieb S, Guedidi H, Reinert L, Amdouni N, Duclaux L (2017) Preparation and characterization of carbons from $\beta$-cyclodextrin dehydration and from olive pomace activation and their application for boron adsorption. J Saudi Chem Soc 21:822-829 
[41] Trotta F, Zanetti M, Camino G (2000) Thermal degradation of cyclodextrins. Polym Degrad Stab 69:373-379

[42] Zhu C, Krumm C, Facas GG, Neurock M, Dauenhauer PJ (2017) Energetics of cellulose and cyclodextrin glycosidic bond cleavage. React Chem Eng 2:201-214

[43] Zanetti M, Anceschi A, Magnacca G, Spezzati G, Caldera F, Rosi GP et al (2016) Micro porous carbon spheres from cyclodextrin nanosponges. Microporous Mesoporous Mater 235:178-184

[44] Cecone C, Zanetti M, Anceschi A, Caldera F, Trotta F, Bracco P (2019) Microfibers of microporous carbon obtained from the pyrolysis of electrospun $\beta$-cyclodextrin pyromellitic dianhydride nanosponges. Polym Degrad Stab 161:277-282

[45] Celebioglu A, Topuz F, Yildiz ZI, Uyar T (2019) One-step green synthesis of antibacterial silver nanoparticles embedded in electrospun cyclodextrin nanofibers. Carbohydr Polym 207:471-479

[46] Yang X, Ke W, Zi P, Liu F, Yu L (2008) Detecting and identifying the complexation of nimodipine with hydroxypropyl- $\beta$-cyclodextrin present in tablets by Raman spectroscopy. J Pharm Sci 97:2702-2719

[47] Ferrari AC, Robertson J (2000) Interpretation of Raman spectra of disordered and amorphous carbon. Phys Rev B 61:14095-14107
[48] Yang Z, Ji H (2013) 2-Hydroxypropyl- $\beta$-cyclodextrin polymer as a mimetic enzyme for mediated synthesis of benzaldehyde in water. ACS Sustain Chem Eng 1:1172-1179

[49] Uyar T, Havelund R, Nur Y, Hacaloglu J, Besenbacher F, Kingshott P (2009) Molecular filters based on cyclodextrin functionalized electrospun fibers. J Membr Sci 332:129-137

[50] Wu HC, Li YY, Sakoda A (2010) Synthesis and hydrogen storage capacity of exfoliated turbostratic carbon nanofibers. Int J Hydrogen Energy 35:4123-4130

[51] Jung I, Dikin D, Park S, Cai W, Mielke SL, Ruoff RS (2008) Effect of water vapor on electrical properties of individual reduced graphene oxide sheets. J Phys Chem C 112:20264-20268

[52] Mettler MS, Mushrif SH, Paulsen AD, Javadekar AD, Vlachos DG, Dauenhauer PJ (2012) Revealing pyrolysis chemistry for biofuels production: conversion of cellulose to furans and small oxygenates. Energy Environ Sci 5:5414-5424

Publisher's Note Springer Nature remains neutral with regard to jurisdictional claims in published maps and institutional affiliations. 